\title{
Variação da posição de nascimento do Sol em função da latitude
}

\author{
Variation of Sunrise Position as a Function of Latitude
}

\author{
Paulo Bedaque*1, Paulo Sergio Bretones ${ }^{2}$ \\ ${ }^{1}$ Chronos Serviços Educacionais Ltda., Vinhedo, SP, Brasil. \\ ${ }^{2}$ Departamento de Metodologia de Ensino, Universidade Federal de São Carlos, São Carlos, SP, Brasil.
}

\begin{abstract}
Recebido em 15 de dezembro de 2015. Revisado em 2 de abril de 2016. Aceito em 3 de abril de 2016
\end{abstract}
\begin{abstract}
Iniciamos o presente artigo discutindo a concepção que, em geral, as pessoas trazem, de que o Sol nasce sempre no ponto cardeal Leste e se põe no Oeste. Para isto apresentamos uma revisão da literatura da área que mostra certa confusão entre alunos pesquisados. São apresentados conceitos relacionados à Esfera Celeste e seu movimento diário bem como o movimento aparente do Sol para observadores de várias latitudes buscando esclarecer tais conteúdos, pré-requisitos para entendimento da questão. Após isso apresentamos uma expressão que permite calcular a posição do nascer do Sol ao longo do ano em função da latitude do observador e a aplicamos para vários casos. Finalmente são apresentados modelos e outros recursos didáticos que permitem abordar tais conteúdos em sala de aula.
\end{abstract}

Palavras-chave: movimento aparente do Sol; nascer e ocaso do Sol, modelos didáticos.

We begin this article discussing about the conception that, in general, people brings up, that the Sun rise always at the cardinal east and set in the west. Here we present a review of the area that shows a bit of confusion amount the students. We show concept related to the celestial sphere and its daily movements also the apparent movement of the Sun to the observers of the various latitudes searching to clarify the contents, prerequisite to clarity this matter. After that we present an expression that allow us to calculate the position of the rise of the Sun towards the year according to the latitude of the observer and we apply it to various cases. Finally, are presented models and others didactic resources that allow us to approach those contents in the classroom.

Keywords: apparent movement of the Sun; sunrise and sunset, didactic models.

\section{Introdução}

No imaginário de muitas pessoas, inclusive de parte dos alunos e professores, o Sol nasce invariavelmente todos os dias no ponto cardeal leste e se põe no ponto cardeal oeste. Segundo acreditam essas pessoas, independentemente do dia do ano, da estação do ano ou da latitude em que elas se encontram, o Sol nasce no leste. Mas a simples observação do nascimento do Sol, dia após dia, nos faz abandonar essa ideia. O Sol, efetivamente não nasce todos os dias no mesmo ponto. Isso sem falar nas regiões da Terra entre os círculos polares e os polos onde a ideia de nascimento do Sol é completamente diferente

*Endereço de correspondência: bedaque@ciencias.com.br daquela que nós, moradores dos trópicos, estamos acostumados. Ocorre que a maioria das pessoas vive em cidades e perdeu o costume de obter informações diretamente da observação dos fenômenos naturais. Essas observações foram trocadas por dados filtrados e avaliações vindos das mídias.

O conhecimento sobre o movimento aparente do Sol é importante para várias áreas. Como exemplo, podemos citar a agricultura, onde certas culturas exigem conhecimento sobre o tempo de insolação a cada dia e ao longo do ano, bem como as diferentes inclinações com que chegam os raios solares. Também na arquitetura é importante conhecer as condições de iluminação mais adequadas às edificações. Para este levantamento são usados aparelhos simuladores 
da trajetória solar aparente. Entre os instrumentos usados em arquitetura e urbanismo está o heliodon. Ele possibilita o levantamento de áreas iluminadas e sombreadas, simulando os movimentos diário e anual do Sol. A Figura 1 apresenta uma foto deste aparelho, conforme mostrado por [1].

As concepções das pessoas sobre o movimento do Sol, bem como o local do seu nascer e ocaso, já foram investigadas por vários autores [2-4] e questões relacionadas foram feitas a alunos e professores de vários níveis escolares em pesquisas realizadas por [5-6]. Um dos trabalhos foi feito com pessoas do hemisfério norte por [7] com uma série de atividades construtivistas destinadas a investigar as concepções de futuros professores do ensino fundamental sobre a causa das estações do ano e características dos movimentos relativos Sol-Terra-Lua. Numa das atividades, perguntou aos alunos: Onde o Sol nasce e onde se põe? Onde está o Sol no céu ao meio-dia? Quantas horas tem o dia (dia claro) de hoje (16 de fevereiro no hemisfério norte)? Nas respostas quatorze alunos responderam que o Sol nasce exatamente no leste, quatro apontaram para uma posição do nascer do Sol à esquerda do leste (mais ao norte), e um deles apontou para uma posição à direita do leste, mais ao sul. A resposta correta é esta última, já que nesta data é inverno no hemisfério norte e, portanto, o Sol como veremos adiante realmente nasce mais ao sul.

Outros autores que publicaram sobre o assunto foram [8]. Em um curso de astronomia com abordagem investigativa, uma das atividades propostas pelos autores era relacionada ao movimento do Sol, ao longo das estações do ano Inicialmente foi usado com os alunos um aplicativo simulando o movimento

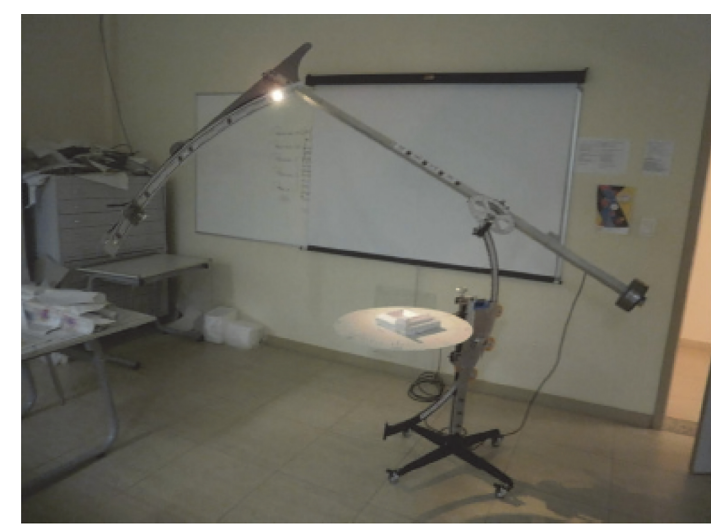

Figura 1: Simulador de trajetória solar aparente. (Fonte Ref. [1]) diurno do Sol no dia 21 de dezembro e foi mostrado como se determina a posição do Sol no horizonte no nascer e no ocaso. Os alunos então foram incumbidos de tabular as posições de nascer e ocaso do Sol para o dia 21 de cada mês, a fim de responder à pergunta: "O Sol nasce e se põe no mesmo lugar no horizonte ao longo do ano, quando se observa do mesmo local?" Pesquisa semelhante pode ser feita por professores no Brasil Mais adiante indicaremos um aplicativo que pode ser usado para a mesma finalidade.

Conforme mencionado por [9] a concepção de crianças e adultos de que "o Sol sempre nasce no leste e se põe sempre no oeste" se deve ao fato de que muitos professores se apoiam nesta ideia. Os autores discutem esta questão propondo a observação e o registro dos fenômenos para vários locais e épocas do ano e uma discussão sobre astronomia de posição.

Também [10] aborda a questão relacionada à variação da posição de nascer e ocaso do Sol a cada dia conforme a latitude do observador. A autora propõe uma atividade com o uso de modelos da esfera celeste e fotos do nascer do Sol para várias latitudes norte e sul, em cidades de vários países. Por meio das fotos e dos modelos, a autora apresenta uma metodologia para verificar as diferentes posições de nascer e ocaso do Sol para cada latitude.

A questão pode ser trabalhada na escola, em especial na disciplina de Física, mas também em Geografia ou mesmo em Ciências nos últimos anos do Ensino Fundamental. Para esclarecer como esses fatos se dão, é preciso entender minimamente como se dá o movimento dos astros quando vistos da Terra e como podemos marcar os acontecimentos com o uso de coordenadas celestes. Para isso, incluímos o item abaixo, sobre a esfera celeste e seus principais elementos.

\section{A Esfera Celeste}

Quando observamos o firmamento, postados na Terra, temos a sensação de ocupar o centro de uma esfera, no interior da qual estariam colocados os planetas, as estrelas, a Lua, o Sol e todos os astros conhecidos. Na verdade, esta sensação não passa de uma ilusão, já que as estrelas estão a diferentes distâncias e não ocupam a parede interior de uma esfera. $\mathrm{O}$ mesmo acontece com os planetas, a Lua, o Sol etc. Mas, para efeitos de localização dos objetos celestes, pensar que ocupamos o centro de uma esfera 
ainda é bastante útil. A essa esfera imaginária, cuja concepção remonta à antiguidade, de raio escolhido arbitrariamente como 1, chamamos de esfera celeste.

Para os povos antigos, as estrelas se movimentam em bloco, ou seja, elas mantêm as posições de uma em relação à outra. Assim, como exemplo, podemos observar Sirius sempre nas proximidades do quadrilátero de Órion, como observavam os antigos gregos ou babilônios. Porém, medidas de posição feitas com maior precisão nos revelam um universo dinâmico, onde as estrelas também se movimentam umas em relação às outras, mas essas variações não são percebidas visualmente em nosso tempo de vida, ou mesmo de uma civilização. Alguns astros, porém, se movimentavam entre as estrelas e chamaram a atenção dos antigos. Estamos falando dos planetas cuja palavra significa "astro errante". Esses últimos estão muito mais próximos de nós e, por este motivo, seus movimentos são mais facilmente percebidos. Outros astros do Sistema Solar, como cometas e asteroides, também têm suas posições alteradas em relação às estrelas.

Para localizar um astro na esfera celeste foram adotados alguns sistemas de coordenadas astronômicas, sendo que vamos enfocar dois deles: sistema horizontal e sistema equatorial. O sistema horizontal, também chamado de sistema alta-azimutal, usa as coordenadas altura (h) e azimute (A) para localizar um astro na esfera celeste (Figura 2). Trata-se de sistema mais simples, mas com o inconveniente de que as coordenadas horizontais dependem da posição do observador sobre a Terra e do horário local. Por este motivo, às vezes este sistema também é chamado de sistema local. A figura abaixo mostra como são definidas as coordenadas altura e azimute.

A altura $\mathbf{h}$ de um astro é a medida angular do ponto ocupado pela estrela na esfera celeste ao hori-

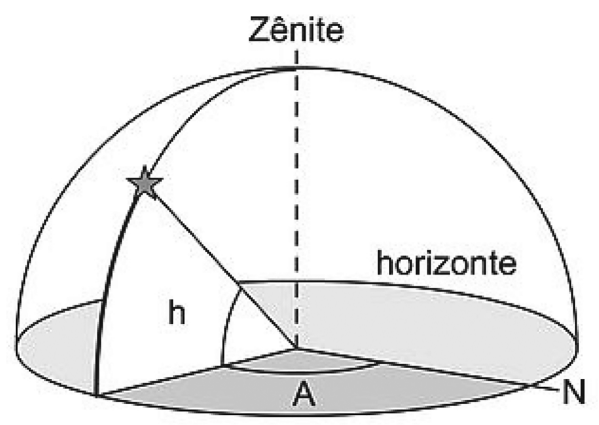

Figura 2: Sistema Horizontal de Coordenadas Celestes. (Fonte Ref. [11]) zonte do observador e varia entre $-90^{\circ}$ e $90^{\circ}$. Para pontos acima do horizonte a altura é definida como positiva $\left(0^{\circ}\right.$ a $\left.90^{\circ}\right)$ e será negativa para pontos abaixo do horizonte (pontos não visíveis). O ponto de altura $90^{\circ}$ é chamado de Zênite e corresponde ao ponto acima da cabeça do observador. Mas apenas esta coordenada não é suficiente para indicar a posição de um astro. A coordenada que completa esse posicionamento é o azimute A. Ele é medido em graus sobre o horizonte, a partir do ponto cardeal norte, no sentido horário (N-L-S-O), como mostra a figura. O ponto norte é uma escolha arbitrária; nada impede que se use outro ponto como referência, como o Sul ou outro qualquer, mas nós usaremos o norte para medidas de azimute. Esta coordenada varia de $0^{\circ}$ a $360^{\circ}$. Com o passar das horas, a altura e o azimute de um astro mudam. Por isso é que dissemos logo acima que as coordenadas do sistema horizontal variam conforme a hora do dia. Como o plano de referência para este sistema, é o horizonte local do observador, essas coordenadas também variam conforme a latitude do observador.

Já o sistema equatorial de coordenadas astronômicas utiliza as coordenadas declinação $(\delta)$ e ascensão reta $(\alpha)$ (Figura 3). Para entender esse sistema, precisamos antes definir o que são equador celeste, eclíptica e eixo do mundo. Considere o eixo da rotação da Terra. Se ele for prolongado dos dois lados, até encontrar a esfera celeste, encontramos um novo eixo chamado eixo do mundo. Os pontos de intersecção do eixo do mundo com a esfera celeste são chamados de polo celeste sul e polo celeste norte. Já o equador terrestre, projetado sobre a esfera celeste, gera um novo círculo, chamado de equador celeste. Ele divide a esfera celeste em dois hemisférios, o hemisfério celeste sul e o hemisfério celeste norte.

A eclíptica corresponde à trajetória da Terra em seu movimento de translação ao redor do Sol, projetada na esfera celeste. Como o eixo da Terra (e, portanto, o eixo do mundo) é inclinado em relação à eclíptica, resulta que o equador celeste será inclinado em $23,5^{\circ}$ com relação à eclíptica, como pode ser observado na figura ao lado. Assim, o equador celeste cruza com a eclíptica em dois pontos indicados como $\Upsilon \mathrm{e} \Omega$. O ponto $\Upsilon$ é chamado de ponto Vernal (ou ponto Gama, algumas vezes).

Para definir as coordenadas do sistema equatorial, usaremos o equador celeste e o ponto $\Upsilon$. Dá-se o nome de declinação $\boldsymbol{\delta}$ de um astro ao seu afastamento angular (medido em graus) do equador celeste. 


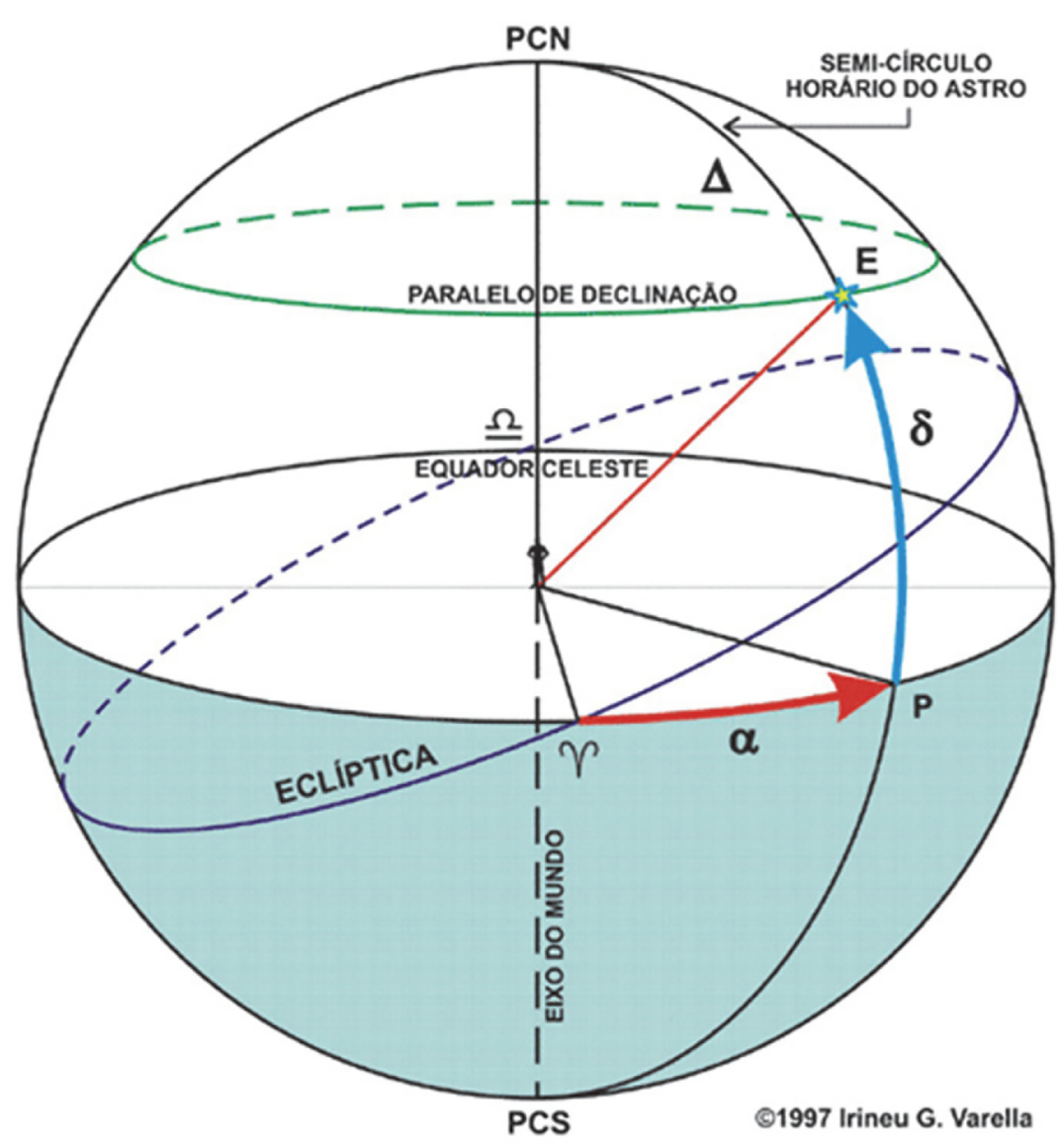

Figura 3: Sistema Equatorial de Coordenadas Celestes. (Fonte Ref. [12]).

Ela varia de $-90^{\circ}$ a $90^{\circ}$ sendo que, por convenção, as declinações são negativas para pontos do hemisfério celeste sul e positivas para aqueles do hemisfério celeste norte. Dá-se o nome de ascensão reta $\alpha$ ao afastamento angular, medido sobre o equador celeste e contado a partir do ponto $\uparrow$. Seu valor costuma ser medido em horas, variando portando de $0 \mathrm{~h}$ a $24 \mathrm{~h}$. A vantagem do sistema equatorial sobre o sistema horizontal é que o primeiro utiliza coordenadas que independem da hora do dia e da posição do observador sobre a superfície da Terra.

\section{Movimento diário da Esfera Celeste}

O movimento de rotação da Terra, de oeste para leste, nos causa a sensação de que a esfera celeste se move o tempo todo de leste para oeste. Assim, os astros nascem no lado leste e se põem no lado oeste. As chamadas estrelas circumpolares são aquelas, que para determinada latitude, estão sempre acima do horizonte, não nascem e nem se põem, por estarem próximas de um dos polos celestes.
A percepção deste movimento diário da esfera celeste é diferente conforme a posição da Terra ocupada pelo observador. Podemos considerar três situações básicas. Primeiramente para um observador postado no equador terrestre (Figura 4b). Como a Terra gira ao redor de seu eixo, que neste caso está sobre o horizonte, o movimento dos astros se dá sobre círculos perpendiculares ao plano do horizonte. O próprio plano do equador celeste é perpendicular ao plano do horizonte. Os astros nascem, atingem sua altura máxima e se põe, sempre levando praticamente o mesmo tempo abaixo e acima do horizonte. Deste ponto da superfície da Terra se pode observar todas as áreas do céu, pois a volta completa de $360^{\circ}$ permite o acesso visual a todas as direções do Universo. De lá não existem estrelas circumpolares, pois todas nascem e se põem.

Já os observadores que vivem em um dos polos têm experiências bem distintas (figura 4c). Como o equador terrestre está sobre o horizonte, o movimento diurno da esfera celeste se dá de modo que os astros descrevam círculos paralelos ao horizonte. As- 


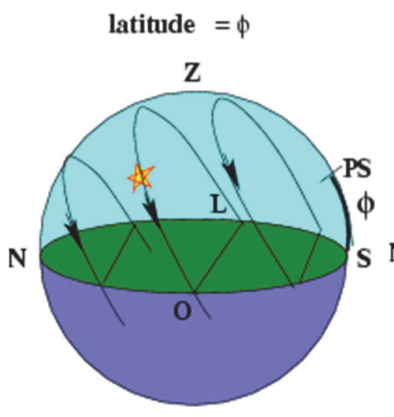

fig. $4 a$

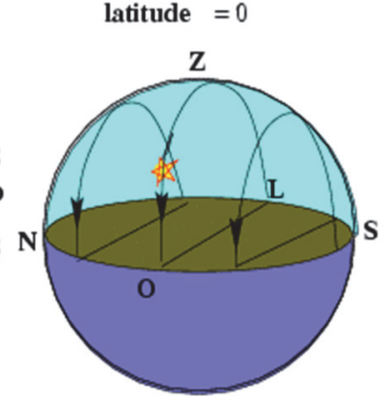

fig. $4 b$

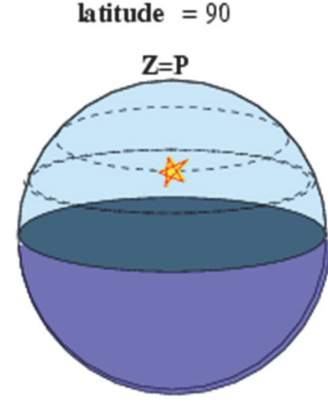

fig. $4 c$

Figura 4: Figuras a, b e c (da esquerda para a direita). Fonte Ref. [13].

sim, só se pode observar um dos hemisférios celestes e todas as estrelas são circumpolares.

Mas a situação mais frequente para a maioria da população mundial não é aquela representada pelas figuras $4 \mathrm{~b}$ e $4 \mathrm{c}$ e sim aquela mostrada na figura $4 \mathrm{a}$, que representa observadores posicionados em uma determinada latitude $\phi$ diferente de $0^{\circ}$ e de $90^{\circ}$. Nessa situação, o equador celeste está posicionado com certa inclinação em relação ao plano do horizonte. Neste caso, todos os astros descrevem arcos inclinados no céu.

\section{Movimento anual do Sol na Esfera Celeste}

A Terra descreve uma órbita elíptica ao redor do Sol, completando uma volta a cada 365,25 dias aproximadamente, ou seja, a cada 1 ano. Como a excentricidade de sua órbita é pequena, ela pode ser aproximada para uma circunferência, o que faremos neste artigo. Como vimos acima, a projeção da órbita da Terra ao redor do Sol sobre a esfera celeste recebe o nome de eclíptica.

Observe a figura 5 , em especial enfocando a posição da Terra em janeiro. Ainda que o intenso brilho do Sol não permita que a vejamos, há, atrás dele uma certa constelação, nesse caso, a constelação de Sagitário. Dizemos, nesse caso, que o Sol está "percorrendo" a constelação de Sagitário. Mas o seu movimento de translação fará com que a Terra ocupe outras posições sobre a eclíptica. Em maio, por exemplo, sua posição é tal que vemos o Sol tendo atrás de si a constelação de Aries. Assim, ao longo do ano, quando visto da Terra, o Sol parece se mover sobre a eclíptica, passando por um grupo de constelações, chamado zodíaco. O nome vem do fato de que a maioria delas têm nomes derivados de animais (zoo

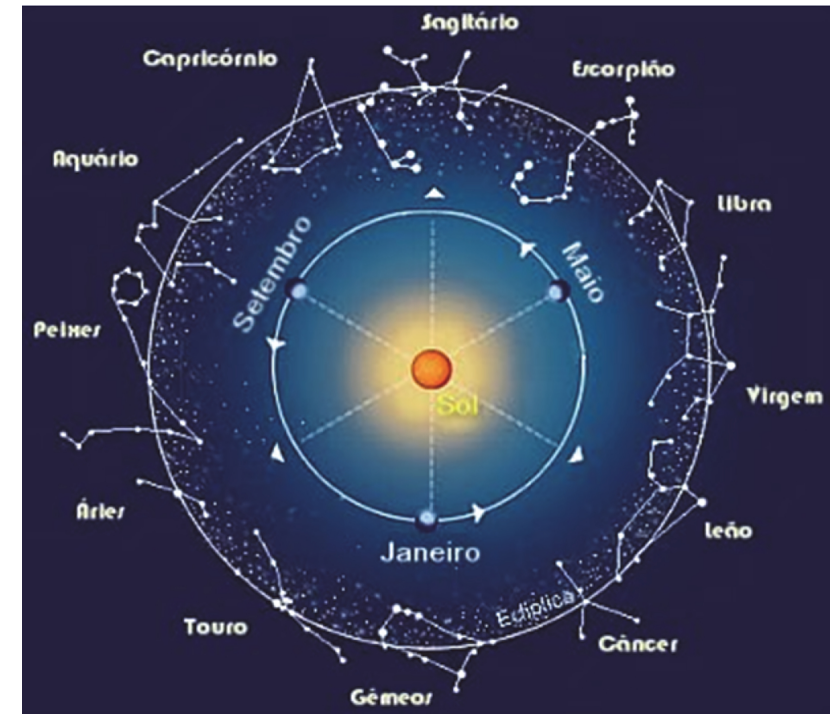

Figura 5: Órbita da Terra e as constelações do Zodíaco. (Fonte Ref. [14])

= animal em grego). A figura 6 mostra o caminho do Sol sobre a eclíptica, quando visto da Terra. Aliás, o nome Eclíptica tem sua origem na palavra eclipse, já que esse fenômeno só ocorre quando a Lua cruza esta linha do céu.

Como veremos a seguir, a inclinação do eixo terrestre, associado ao movimento de translação de da Terra, é que explica que o Sol nasce em diferentes

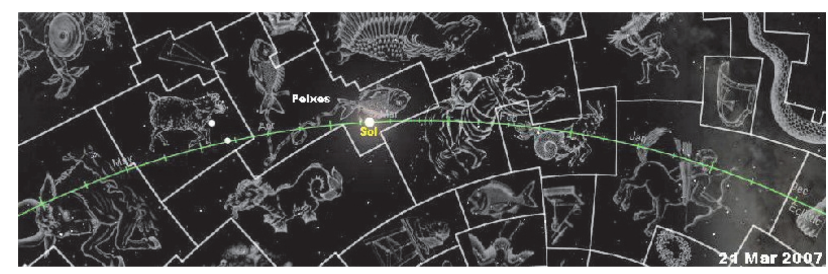

Figura 6: Movimento anual do Sol sobre a eclíptica. (Fonte Ref. [15]) 


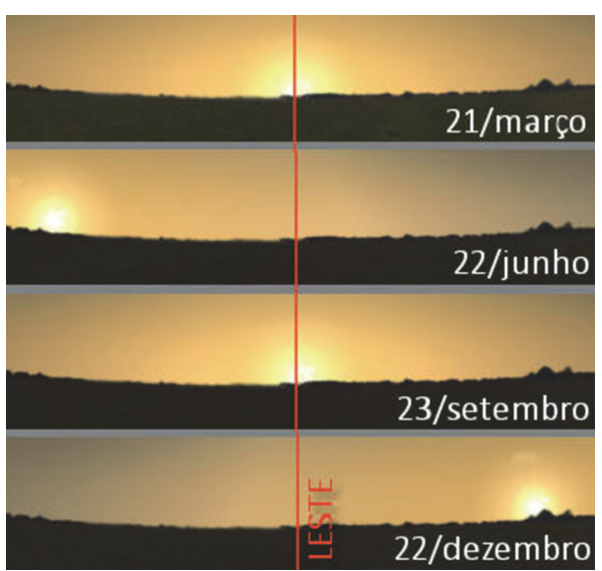

Figura 7: Variação da posição onde o Sol nasce ao longo do ano. (Fonte Ref. [16])

pontos do horizonte ao longo do ano. Uma maneira fácil de perceber esse fato é usar algum referencial terrestre, como um poste, uma árvore ou mesmo a borda de uma janela. Observando-se o nascer do Sol, sempre do mesmo ponto, poderemos, através desses referenciais, perceber que ele nasce em pontos diferentes do horizonte ao longo do ano (Figura 7).

Para observadores do hemisfério sul da Terra, após o início da primavera e no verão, o Sol nasce à esquerda do leste, mais ao Norte e após o início do outono e no inverno, à direita do leste, mais ao sul. Muitas das culturas indígenas, inclusive do Brasil, observam o nascimento do Sol todos os dias e com isso acompanham o andar do ano e as mudanças de estações. Eles aprenderam também a estimar a hora do dia pela altura do Sol, coisa que a maioria de nós trocou por instrumentos como celulares e relógios de pulso. Nós, das grandes cidades, dependemos dos calendários (impressos ou virtuais) e de outras informações vindas da mídia ou de relógios para saber se saímos da primavera e entramos no verão, ou se já passamos do meio-dia e está na hora do almoço. Esta falta de observação dos fenômenos naturais nos parece ser a principal causa da falsa crença das pessoas de que o Sol nasce sempre no leste.

Escolhido um ponto de observação, se ao longo do ano, sempre no mesmo horário, anotarmos a posição do Sol na esfera celeste, chegaremos a uma figura chamada analema. É possível fotografar um analema, com uma câmera fixa num ponto e disponível por um ano. As fotos não precisam ser diárias e podem ser feitas a cada 9 dias, mais ou menos. Não é uma tarefa fácil, mas o resultado é surpreendente.
A figura 8 mostra uma dessas. Ela mostra os pontos extremos de nascimento do Sol, bem como os diferentes horários em que ele nasce.

\section{Afinal, onde nasce o Sol?}

O Sol se move na esfera celeste ao longo da eclíptica durante o ano. Dessa forma, cruza o equador celeste em duas ocasiões, como se pode ver na figura 9. Essas datas coincidem com os inícios da primavera e do outono. Por causa deste movimento, a declinação do Sol (afastamento com relação ao equador) varia entre $-23,5^{\circ}$ a $23,5^{\circ}$, aproximadamente. As declinações negativas indicam que o Sol está no hemisfério celeste Sul enquanto as positivas indicam que ele se encontra no hemisfério celeste norte.

Essa variação de declinação ao longo do ano é que resulta em diferentes trajetórias do Sol, para cada observador, ao longo do dia. Tomando como exemplo um observador em uma latitude intermediária, como já mostrado na figura $4 \mathrm{a}$, todos os astros visíveis descrevem arcos inclinados no céu.

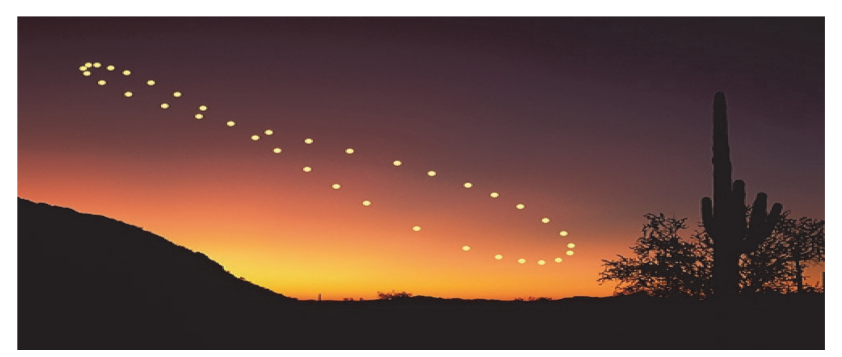

Figura 8: Os diferentes pontos e horários de nascimento do Sol ao longo do ano, formam uma figura conhecida como analema. (Fonte Ref. [17])

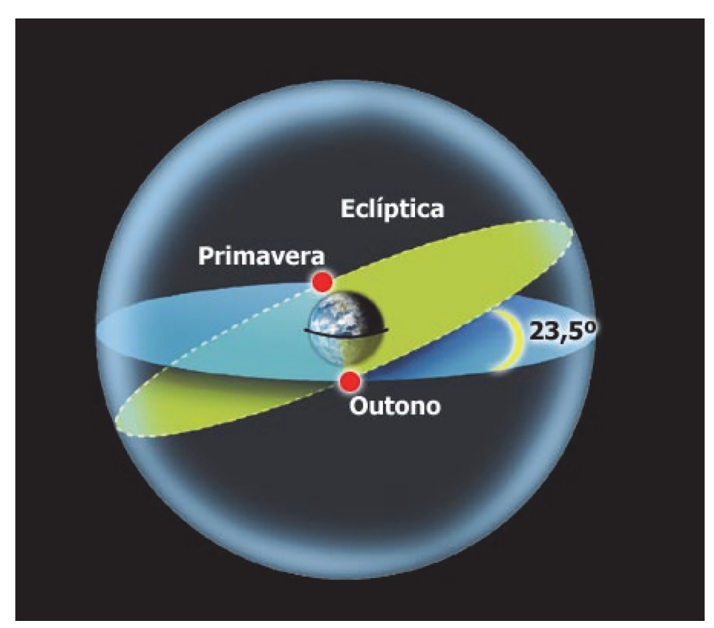

Figura 9: Inclinação da eclíptica em relação ao equador celeste. (Fonte Ref. [18]) 
Observe a figura 10. Quando a declinação do Sol é $-23,5^{\circ}$, sua trajetória ao longo daquele dia, será a indicada pelo arco mais à direita. Já, quando sua declinação é zero, ou seja, ele está sobre o equador celeste, descreverá ao longo do dia, o arco do meio. $\mathrm{O}$ arco mais à esquerda corresponde à declinação $+23,5^{\circ}$. Os pontos onde o equador celeste cruza o horizonte são os chamados pontos cardeais leste e oeste. Por esta figura já se pode observar que, o ponto de nascimento do Sol varia bastante ao longo do ano. Na entrada do verão no hemisfério sul, o Sol nasce bem à direita do leste. Já no início do inverno, nasce bem à esquerda do leste. Em verdade, nasce no leste apenas dois dias do ano, ou seja, apenas $0,55 \%$ das vezes. Para o caso de um observador que esteja sobre equador terrestre, o Sol também nasce, nos pontos mais extremos, à direita ou a esquerda do leste. Já no caso de observadores nos polos, onde o equador coincide com o horizonte, ora o Sol está acima, ora está abaixo dele. Assim, para este observador, haverá dia com duração de seis meses seguido de uma noite de mesma duração.

\section{Calculando a variação da posição do nascer do Sol}

A variação da declinação do Sol ao longo do ano leva muitos a pensarem que o ponto de seu nascimento oscila em relação ao ponto leste, $23,5^{\circ}$ para um lado e esta mesma medida para o outro, resultando numa

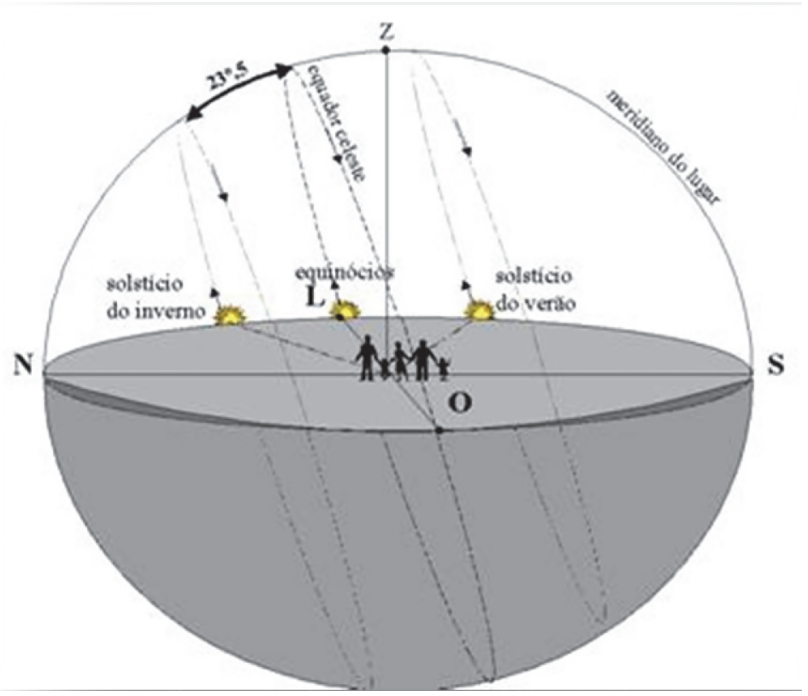

Figura 10: Movimento do Sol, nascendo em diferentes posições, nas diferentes estações do ano, para uma latitude intermediária. (Fonte Ref. [19]) variação angular total de $2 \times 23,5^{\circ}$, ou seja, de $47^{\circ}$. Mas mostraremos adiante que este nem sempre é o caso. Isso só ocorre para observadores postados no equador, como mostra a figura 11 . A variação angular depende da latitude do observador e pode ser muito maior que $47^{\circ}$. Por exemplo, para um observador postado na latitude $60^{\circ}$ o Sol nasce entre pontos extremos no horizonte que "distam" entre si $105^{\circ}$.

Pela figura 11, podemos perceber que a amplitude de declinação do Sol, ou seja, $47^{\circ}$, não corresponde necessariamente à amplitude da posição do nascer do Sol no horizonte. Apesar de se tratar de um triângulo esférico, fazendo uma analogia com a geometria plana, tudo se passa como se a declinação fosse um cateto (b) enquanto o afastamento angular ao ponto Leste fosse uma hipotenusa (a). Assim, o arco a será sempre maior ou igual ao arco b. Além disso, quanto mais inclinado for o equador com relação ao horizonte, o que acontece quanto maior a latitude, maior será o valor do arco a no horizonte.

Mas como saber qual a declinação do Sol em determinado dia? Na literatura da área [20] podemos encontrar as demonstrações das equações que mostraremos a seguir. Desprezando-se a excentricidade da órbita da Terra, podemos calcular a declinação do Sol por:

$$
\delta=-23,44 \cdot \cos \left(\frac{2 \pi}{365} \cdot(\mathrm{T}+10)\right)
$$

onde $\mathrm{T}=$ número do dia do ano $(1 \leqslant \mathrm{~T} \leqslant 365)$

Abaixo mostramos o gráfico desta função, onde se pode estimar a declinação do Sol para cada dia. Notase que o maior valor da declinação (mais exatamente $23,45^{\circ}$ ) ocorre por volta dia 21 de junho(*), que

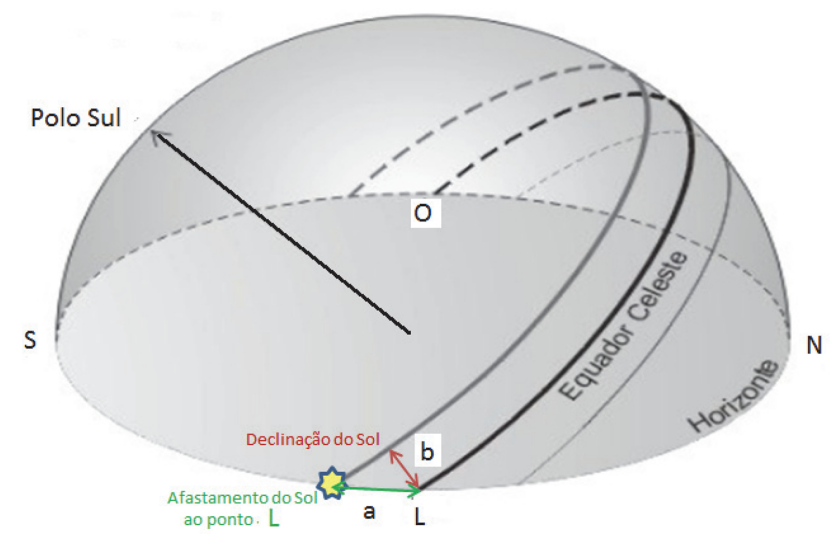

Figura 11: Posição do nascer do Sol mostrando o afastamento angular (a) em função da declinação (b). 


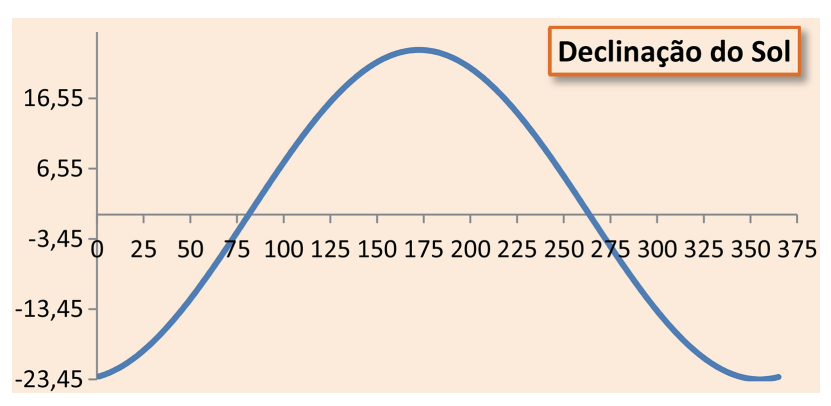

Figura 12: Gráfico mostrando a variação da declinação do Sol ao longo do ano.

corresponde à data do solstício (verão no norte e inverno no sul).

Já o azimute do Sol no instante de seu nascimento, pode ser encontrado pela expressão abaixo:

$$
A=\operatorname{arc} \cos (-\operatorname{sen} \delta / \cos \phi)
$$

onde $\delta=$ declinação do Sol e $\phi=$ latitude local.

Como exemplo, tomemos a cidade de São Paulo, cuja latitude é de aproximadamente $23,5^{\circ}$. No solstício do verão no hemisfério Sul, que ocorre em 22 de dezembro $(*)$, a declinação do Sol vale $\delta=-23,45^{\circ}$. Assim, o azimute do Sol neste dia será $\mathrm{A}_{1}=$ arc $\cos \left[-\operatorname{sen}\left(-23,45^{\circ}\right) / \cos \left(23,5^{\circ}\right)\right]=64,3^{\circ}$. Para o dia do solstício de inverno, 21 de junho(*), para S. Paulo, encontramos $\mathrm{A}_{2}=115,7^{\circ}$. A diferença entre esses azimutes nos fornece a amplitude entre os pontos extremos de nascimento do Sol no horizonte. Neste caso, este valor é de $\mathrm{A}_{2}-\mathrm{A}_{1}=51,4^{\circ}$. Isso mostra que nem o Sol nasce sempre no Leste como essas amplitudes não se limitam ao valor de $47^{\circ}$ como alguns imaginam. A tabela 1 nos mostra essas amplitudes calculadas para outros pontos.

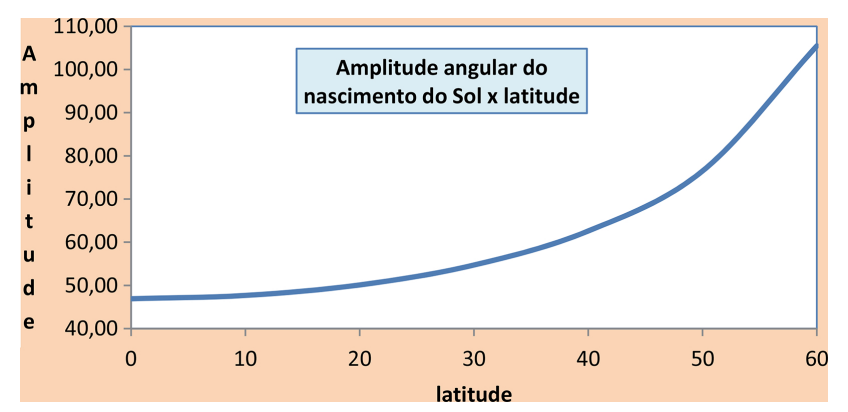

Figura 13: Gráfico mostrando a variação da Amplitude angular dos pontos de nascimento do Sol, em função da latitude do observador.

\section{Modelos Didáticos}

Além da matemática exposta acima, seria interessante concretizar esses conceitos com seus alunos, usando modelos. Um modelo simples, conforme proposto por [21], e adaptado por nós, pode ser feito facilmente na escola usando-se três copos descartáveis de água e um pequeno usado para café, uma esfera de isopor de mais ou menos $10 \mathrm{~cm}$ de diâmetro, um palito de churrasco, um pequeno alfinete e uma coroa circular de cartolina, com raios interno e externo de aproximadamente $11 \mathrm{~cm}$ e $16 \mathrm{~cm}$ (Figura 14). Você precisará também duas canetas hidrográficas de cores diferentes. A esfera de isopor fará o papel da esfera celeste e o palito o seu eixo de rotação. Colocado o eixo, deve-se desenhar o equador celeste, mostrado em vermelho na foto. Deve-se também desenhar a eclíptica em verde, com uma inclinação de $23,45^{\circ}$. Se posicionarmos a esfera no meio da coroa, podemos simular estar a uma latitude qualquer, por exemplo, $45^{\circ}$. O Sol poderá ser marcado sobre a eclíptica nas posições de solstícios, que são as mais afastadas do equador (declinações máximas), o que pode ser feito também usando-se um alfinete.

Tabela 1: Exemplos de cidades, com diferentes latitudes, mostrando o azimute do nascimento do Sol no solstício de verão, no solstício de inverno e a correspondente amplitude. O gráfico a seguir (Figura 13) apresenta a variação dessas amplitudes em função da latitude do observador.

\begin{tabular}{lcrcc}
\hline Cidade & Latitude & Solstício de Verão & Solstício de Inverno & Amplitude \\
\hline Macapá & 0,0 & 66,6 & 113,5 & 46,9 \\
Fortaleza & $-3,7$ & 66,5 & 113,5 & 47,0 \\
Salvador & $-13,0$ & 65,9 & 114,1 & 48,2 \\
Brasília & $-15,8$ & 65,6 & 114,4 & 48,8 \\
S. Paulo & $-23,5$ & 64,3 & 115,7 & 51,4 \\
Porto Alegre & $-30,0$ & 62,7 & 117,3 & 54,6 \\
Londres & 51,5 & 50,3 & 129,7 & 79,4 \\
Ushuaia & $-54,8$ & 46,4 & 133,7 & 87,3 \\
Estocolmo & 59,3 & 38,8 & 141,2 & 102,4 \\
\hline
\end{tabular}




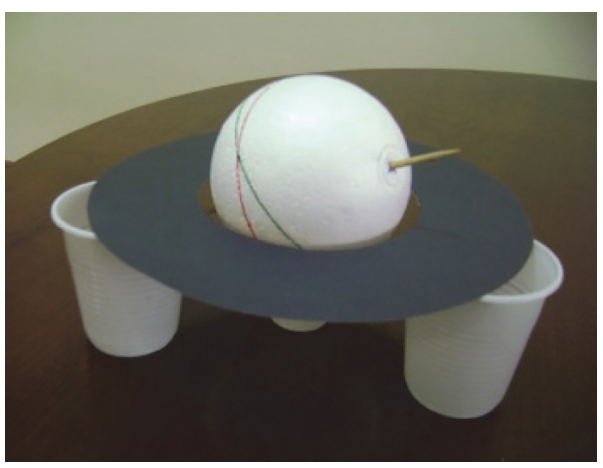

Figura 14: Modelo de isopor para a esfera celeste. Modelo de globos da esfera celeste. Fonte: Fotos de Paulo S. Bretones

Primeiramente, vamos supor que o Sol esteja na máxima declinação norte. Se for girada a esfera, pode-se simular o instante em que o Sol nasce. Esta posição pode ser marcada na cartolina, que faz o papel de horizonte do observador. Se repetirmos este procedimento, supondo agora o Sol no ponto de máxima declinação sul, igualmente podemos marcar a posição de seu nascimento no horizonte. Com essas duas posições marcadas, pode-se observar a amplitude do nascer do Sol para aquela latitude.

Se o leitor quiser conhecer outro modelo vale a pena consultar o trabalho de [22]. Nele usa-se um cd como alternativa ao uso da cartolina para representar o horizonte e uma fita de acetato onde se marca o equador celeste e a eclíptica $\mathrm{O}$ modelo proposto por [23] para simular o movimento aparente do Sol na esfera celeste também é útil para o nosso propósito, ou seja, analisar os diferentes pontos de nascimento do Sol no horizonte. Nesta proposta, usa-se um arco de arame móvel, onde se posta o Sol usando-se uma pequena bola de isopor. Este arco em movimento mostra ao estudante a trajetória do Sol ao longo do dia. Um modelo clássico foi proposto por [24] usando um balão de vidro, desses usados em laboratórios de química. Nele se desenha a eclíptica e o equador celeste e o horizonte é representado pela superfície livre de água, colocada dentro do balão (figura 15).

Também [25] propõe um modelo onde são usados arcos de arame para representar o meridiano local e o equador celeste. Para posicionar o equador celeste no modelo são usadas fotografias do nascer e do pôr do Sol no primeiro dia da primavera ou do outono, obtendo-se a exata posição dos pontos cardeais leste e oeste. O mesmo se faz nos dias de solstícios e são fixados outros dois arames paralelos ao equador, onde se pode formar a área de movimentação

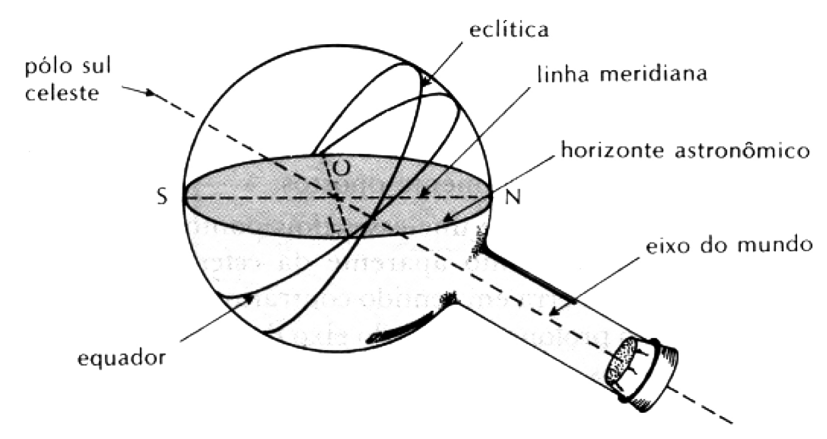

Figura 15: Modelo de esfera celeste com balão de vidro (Fonte Ref. [25])

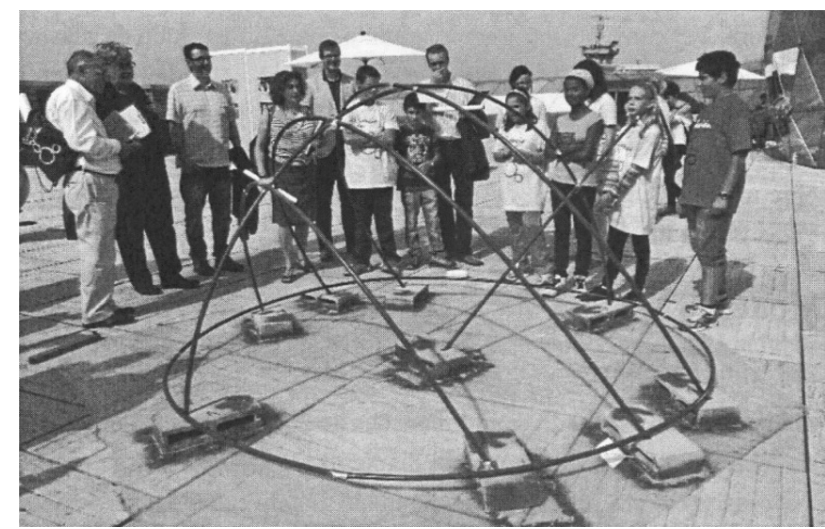

Figura 16: Modelo com arcos representando os elementos da esfera celeste (ou meridiano local, o equador, trajetória do Sol nos equinócios ...) (Fonte Ref. [25])

do Sol ao longo do ano. Alguns desses modelos foram construídos numa escala tal que permitia que um aluno ocupasse o seu interior para uma melhor visualização dos elementos geométricos da esfera celeste.

Outro recurso didático que pode ser usado é a página disponibilizada pela Universidade de Nebraska [26]. Trata-se de um simulador dos movimentos do Sol onde se pode fixar a latitude do observador, uma determinada data e com isso observar o movimento do Sol na esfera celeste. Visitando a página, escolhemos, como exemplo, a latitude de $-30^{\circ}$ e o dia 21 de junho. A tela apresentada é mostrada na figura 17, com o nascer do Sol aproximadamente as 7 h da manhã. Repare que o Sol está nascendo à esquerda do leste, já que em junho no hemisfério sul, estamos no inverno. Se clicarmos no botão "start animation", podemos observar o movimento diário do Sol nesta data e local. Sugerimos uma visita à página para experimentar outros dias e latitudes. 


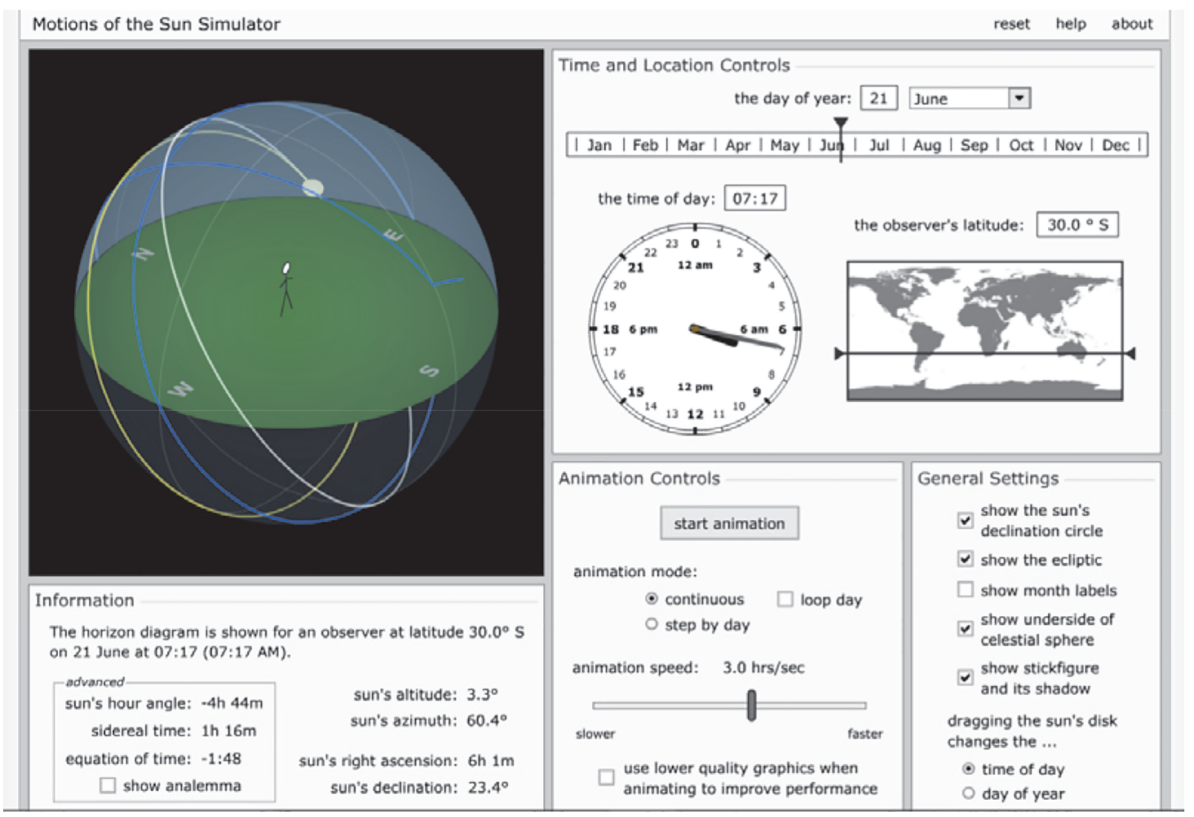

Figura 17: Página referente ao simulador dos movimentos do Sol disponibilizada pela Universidade de Nebraska (Fonte Ref. [26])

\section{Conclusão}

Os resultados de pesquisas com esse tema mostram que existe, de modo razoavelmente disseminado, concepções erradas sobre os pontos onde o Sol nasce e se põe no horizonte. Este artigo propôs o enfrentamento dessa questão, utilizando o conhecido sobre os elementos da esfera celeste, bem como o uso de ferramentas da trigonometria esférica e do uso de recursos didáticos ao alcance da grande maioria dos alunos e professores. O artigo não pretende esgotar o assunto; ao contrário, esperamos que tais recursos sejam usados nas escolas e que professores se interessem pelo assunto, gerando novos trabalhos e novas experiências. Com isso podem ser desenvolvidos novos estudos, sobretudo baseados na realidade de nosso país, com referência às concepções dos alunos, à metodologia de ensino de tais conteúdos e outros recursos didáticos.

\section{Referências}

[1] L.C. Fernandes, J. Grzybowski e A. Ribeiro, in: Encontro Nacional e Encontro Latino Americano de Conforto no Ambiente Construído, $10^{\circ} \mathrm{ENCAC}$ (2013).

[2] B.M. Sebastià, Revista Latino-Americana de Educação em Astronomia 1, 7 (2004).

[3] R. Langhi e R. Nardi, Cad. Bras. Ens. Fís. 24, 87 (2007).
[4] R. Langhi, Cad. Bras. Ens. Fís. 28, 373 (2011).

[5] M.D. Longhini e I.M. Mora, in: Educação em Astronomia na Escola: Experiências e Contribuições para a Prática Pedagógica, organizado por M.D. Longhini (Átomo, Campinas, 2010), p. 87-115.

[6] D.I. Machado e C. Santos, Revista LatinoAmericana de Educação em Astronomia 11, 7 (2011).

[7] R. Trumper, Journal of Research in Science Teaching 43, 879 (2006).

[8] S.L. Slater, T.F. Slater e A. Shaner, Journal of Geoscience Education 56, 408 (2008).

[9] N. Camino y R.M. Ros, Educación en Ciencias 1, 11 (1997).

[10] R.M. Ros, in: Proceedings of 6th EAAE International Summer School, Barcelona (2002), p. 177, p. 188.

[11] Documentação disponível em http://pt wikipedia.org/wiki/Sistema_horizontal_ de_coordenadas.

[12] Documentação disponível em http://www uranometrianova.pro.br/cursos/astronomia_ esferica01/esferica1060.htm, consultada em $23 / 11 / 2015$.

[13] Documentação disponível em www.if.ufrgs.br/ fis02001/aulas/mov_apar_astro.htm, consultada em 23/11/2015.

[14] Documentação disponível em http:// fisicamoderna.blog.uol.com.br/arch2007-1104_2007-11-10.html, consultada em 23/11/2015.

[15] Documentação disponível em http://astro.if ufrgs.br/const.htm, consultada em 23/11/2015. 
[16] Documentação disponível em http:// fisicamoderna.blog.uol . com.br/arch2009-1220_2009-12-26.html, consultada em 23/11/2015.

[17] Documentação disponível em http://noticias. eltiempo.es/2015/10/04/analema-que-escomo-fotografiarlo/

[18] Documentação disponível em http:// revistagalileu.globo.com/EditoraGlobo/ componentes/article/edg_article_print/0, 3916, 900784-1941-2,00.html, consultada em $23 / 11 / 2015$.

[19] Documentação disponível em http://www.das. inpe.br/ciaa/cd/HTML/dia_a_dia/1_5_2.htm, consultada em 23/11/2015.

[20] R. Boczko, Conceitos de Astronomia (Edgard Blücher Ltda, São Paulo, 1984), 429 p.

[21] C.A. Kantor e L.C. Menezes, Os Astros e o Cosmo (Escolas Associadas, São Paulo, 2002).

[22] F.S. da Silva, F. Catelli e O. Giovannini, Caderno Brasileiro de Ensino de Física 27, 7 (2010).

[23] D.I. Machado, in: Ensino de Astronomia na Escola: Concepções, Ideias e Práticas, organizado por M.D. Longhini (Átomo, Campinas, 2014), p. 253-273.

[24] R. Caniato, O Céu (Átomo, Campinas, 2011).

[25] R.M. Ros, in: in: Ensino de Astronomia na Escola: Concepções, Ideias e Práticas, organizado por M.D. Longhini (Átomo, Campinas, 2014), p. 215-236 e figura na p. 232.

[26] Documentação disponível em http://astro.unl edu/naap/motion3/animations/sunmotions . html, consultada em 23/11/2015. 